\title{
Generic recall during posthypnotic amnesia
}

\author{
JOHN F. KIHLSTROM \\ Harvard University, Cambridge, Massachusetts 02138
}

and

\author{
FREDERICK J. EVANS \\ The Institute of Pennsylvania Hospital, Philadelphia, Pennsylvania 19139 \\ and University of Pennsylvania, Philadelphia, Pennsylvania 19174
}

\begin{abstract}
"Generic recall" occurs when the person has the idea of the general nature of the information that is to be remembered, but cannot gain complete access to the particular memory. Memory reports from 725 hypnotized subjects were inspected by independent blind raters for instances of generic recall. During suggested posthypnotic amnesia, generic recall occurred significantly more often in the memory reports of hypnotizable than insusceptible subjects, and was inversely related to the actual number of items recalled. There was a marked shift from generic to particular recall after the amnesia was lifted. Posthypnotic amnesia may provide a useful method for the study of episodic memory for personal experiences.
\end{abstract}

The experience in which a certain memory is "on the tip of the tongue" occurs with disconcerting frequency under natural circumstances: searching for one's car keys, trying to remember a date or mathematical formula during an examination, and struggling to attach a name to a face at a cocktail party are familiar examples. A person in such a state has the "feeling of knowing" the critical material (Hart, 1965) and also can typically produce some fragment or partial description of the target memory (Brown \& McNeil, 1966). Brown and McNeil (1966) termed this latter aspect "generic recall": The person has the idea of the to-beremembered information, but cannot gain complete access to it.

Similar observations have been made in hypnotized subjects who are experiencing suggested posthypnotic amnesia, that is, who are unable to remember post-

This study was conducted at the Unit for Experimental Psychiatry, The Institute of Pennsylvania Hospital, and was supported in part by Grant MH-19156 from the National Institute of Mental Health, United States Public Health Service, and in part by a grant from the Institute of Experimental Psychiatry. J. F. Kihlstrom served as one of the blind raters throughout, and was joined by Maribeth A. Miller on Sample A and Mary Anne Iselin and Martin Korn on Sample B; F. J. Evans served as the third judge who resolved our disagreements. The standardized scoring criteria were developed by the authors collaboratively with Maribeth A. Miller and Emily Carota Orne. We thank Paul Rozin for giving us access to Sample A, and our colleagues for their helpful comments during the preparation of this paper: Heather A. Brenneman, A. Gordon Hammer, Pamela A. Markowsky, Emily Carota Orne, Martin T. Orne, Helen M. Pettinati, William M. Waid, and Stuart K. Wilson. Address reprint requests to John F. Kihlstrom, Department of Psychology and Social Relations, Harvard University, William James Hall, 33 Kirkland Street, Cambridge, Massachusetts 02138; or Frederick J. Evans, Unit of Experimental Psychiatry, The Institute of Pennsylvania Hospital, 111 North 49th Street, Philadelphia, Pennsylvania 19139. hypnotically the events and experiences that transpired during hypnosis until the experimenter cancels the suggestion by administering a prearranged cue (for reviews, see Cooper, 1972; Hilgard, 1965, 1966, 1977; Kihlstrom, 1977; Kihlstrom \& Evans, in press; Orne, 1966). After hypnosis has been terminated, amnesia is tested by asking the subject to recall what has happened while he or she was hypnotized. Some subjects, in fact, seem unable to remember any of the events. Nonetheless, they acknowledge that something occurred-they just cannot remember exactly what it was.

Often, the amnesic subject is able to remember some aspect of one or more of the suggestions, without remembering the rest. For example, a subject in one of our experiments reported, "I wrote my name," a clear if incomplete reference to a point in the experimental procedure where she was regressed first to age 10 and then to age 7 , vividly recalled her 5 th- and 2 nd-grade classrooms, conversed at length with the experimenter about her teachers, classmates, and school activities, and wrote her name (as well as other things) several times. Amnesic subjects may be so vague in recall that it is unclear, even to an experienced investigator, exactly what it is that they are remembering. Another subject, for example, said, "I did something with my hand-I think," following an experiment that included no less than four separate suggestions concerned with movements of his hands and arms. Yet a third subject responded with, "There was something said about heaviness," a remark that could refer either to a phrase repeated often during the hypnotic induction procedure or to one of two specific suggestions involving feelings of heaviness in the hands and arms. Following the usage established by Brown and McNeil (1966), we have come to refer to this phenomenon as a kind of generic recall. The purpose of the present study was to document our 
informal observations of generic recall during posthypnotic amnesia.

\section{METHOD}

\section{Subjects}

A total of 725 male and female college student volunteers received one of five slightly modified versions of the Harvard Group Scale of Hypnotic Susceptibility, Form A (HGSHS:A) (Shor \& Orne, 1962), a standardized hypnotic procedure containing a series of 12 representative hypnotic suggestions scored according to objective behavioral criteria. Sample A $(N=237)$ consisted of introductory psychology students at the University of Pennsylvania who were tested during a routine classroom demonstration; Sample $B(N=488)$ consisted of subjects who were paid for their participation in a formal experiment. On the basis of their HGSHS:A scores, the subjects were classified as low (0-4 items passed, $\mathrm{N}=111$ for the two samples combined), medium (5-8 items passed, $N=388)$, or high $(9-12$ items passed, $\mathrm{N}=226$ ) in susceptibility to hypnosis. Subjects of medium hypnotizability were excluded from subsequent analyses.

\section{Procedure}

The HGSHS:A contains a suggestion of temporary posthypnotic amnesia for the nine suggestions that are administered while the subject is hypnotized. Response to the amnesia suggestion was evaluated by a series of written recall tests each lasting $3 \mathrm{~min}$. Initial amnesia: Immediately after the termination of hypnosis and testing of response to another posthypnotic suggestion, all subjects were asked to recall the things that they did or experienced while they were hypnotized. (Those subjects who recalled three or fewer of the nine critical items were considered to pass the standardized criterion for posthypnotic amnesia.) Postamnesia: A prearranged cue was given to cancel the amnesia suggestion and the subjects were asked to report every thing that they then remembered, regardless of whether they had recalled it before.

The subjects' written memory reports were then evaluated by two experienced raters who were blind to the hypnotizability of the subjects, working independently on the basis of standardized criteria developed earlier. Any discrepancies were resolved by discussion and, if necessary, appeal to yet a third blind judge. Instances of generic recall could be readily identified by this procedure when the raters agreed that the subject was referring to some hypnotic event in his or her memory report, but also agreed that the particular referent could not be confidently established. For example, five suggestions on HGSHS:A involve the hands and/or arms. Records that contained reports such as "I did something with my hands" were labeled generic because they could refer to any of five specific items; reports such as "I raised my left hand, it grew heavy and fell down" were labeled particular, as there was only one such item.

\section{RESULTS}

The parameters of HGSHS:A response were similar in the two samples, and closely paralleled established norms (Sample A, N = 237: $\mathrm{M}=7.07, \mathrm{SD}=2.38$, amnesia pass $=40.1 \%$; Sample $B, N=488: M=7.09$, $\mathrm{SD}=2.58$, amnesia pass $=44.3 \%$ ).

\section{Rater Reliability}

The two raters showed a high degree of agreement in their scoring of the amnesia tests. In Sample A, for which the most extensive reliability information was available, the 237 subjects recalled a total of 930 individual scale items during the initial amnesia test. The raters agreed in their evaluations of 887 (95.4\%) of these. Half of the 43 discrepancies resulted from disagreements as to the precise content of an item; the remaining errors represented either the erroneous scoring of an item as recalled or the inadvertent oversight of an item. The two raters agreed on the number of items recalled in 216 of the 237 subjects $(91.1 \%)$. Resolution of the 21 cases of disagreement resulted in changing the pass-fail amnesia score of only three subjects (1.3\% of the entire sample). A similarly high level of interrater reliability was apparent in Sample B.

\section{Generic Recall}

Table 1 compares the incidence of generic and particular recall on the initial amnesia test for the hypnotizable and insusceptible subjects of the two samples taken separately. Those subjects who were completely amnesic $($ recall $=0$ ) could show neither generic nor particular recall; accordingly, they were excluded from this analysis $(\mathrm{N}=17$ and 53 in Samples A and B, respectively). In Sample A, generic recall occurred during amnesia testing in $29.6 \%$ of the remaining 54 hypnotizable subjects, but only $6.3 \%$ of the remaining 32 insusceptible subjects; in Sample B, the corresponding figures were $19.8 \%$ and $6.2 \%$, respectively. The difference was significant by a chi-square test in both cases $(\mathrm{p}<.05)$.

When the two samples were combined, the pattern of generic and particular recall occurring during and after amnesia became quite clear, as shown in Table 2 . Again those with complete amnesia (recall $=0$ items) on the initial amnesia test were excluded from the analysis. During amnesia, $22.9 \%$ of the hypnotizable subjects but only $6.2 \%$ of the insusceptible subjects showed generic recall, a highly significant difference. On the postamnesia test the incidence of generic recall fell to only $6.5 \%$ of the hypnotizable subjects and $1.0 \%$ of the insusceptible subjects, a difference that does not reach an acceptable level of statistical significance.

Table 1

Incidence of Generic (G) and Particular (P) Recall During Posthypnotic Amnesia

\begin{tabular}{lcrcc}
\hline & \multicolumn{4}{c}{$\begin{array}{c}\text { At Least Some } \\
\text { Recall }\end{array}$} \\
\cline { 3 - 4 } Group & $\begin{array}{c}\text { Complete } \\
\text { Amnesia* }\end{array}$ & $\mathrm{G}$ & $\mathrm{P}$ & $\chi^{2}$ \\
\hline Sample A & & & & \\
$\quad$ Hypnotizable & 14 & 16 & 38 & \\
$\quad$ Insusceptible & 3 & 2 & 30 & $5.30^{* *}$ \\
Sample B & & & & \\
$\quad$ Hypnotizable & 42 & 23 & 93 & \\
Insusceptible & 11 & 4 & 61 & $5.11^{* *}$ \\
\hline
\end{tabular}

${ }^{*}$ Recall $=0$ on initial amnesia test; these cases were excluded from the chi-square test. $\quad{ }^{* *} p<.05(d f=1)$. 
Table 2

Incidence of Generic (G) and Particular (P) Recall During and After Posthypnotic Amnesia: Combined Sample

\begin{tabular}{ccrrr}
\hline & \multicolumn{4}{c}{$\begin{array}{c}\text { At Least Some } \\
\text { Recall }\end{array}$} \\
\cline { 3 - 4 } Condition & $\begin{array}{c}\text { Complete } \\
\text { Amnesia* }\end{array}$ & $\mathrm{G}$ & $\mathrm{P}$ & \\
\hline $\begin{array}{c}\text { Initial Amnesia } \\
\text { Hypnotizable }\end{array}$ & 56 & 39 & 131 & \\
$\quad$ Insusceptible & 14 & 6 & 91 & $11.21^{* *}$ \\
$\begin{array}{c}\text { Postamnesia } \\
\text { Hypnotizable }\end{array}$ & 56 & 11 & 159 & \\
Insusceptible & 14 & 1 & 96 & 3.08 \\
\hline
\end{tabular}

${ }^{*}$ Recall $=0$ on initial amnesia test; these cases were excluded from the chi-square test. $\quad{ }^{* *} p<.05(d f=1)$.

Table 3

Shif ts Between Generic and Particular Recall After Cancelling Posthypnotic Amnesia

\begin{tabular}{lccc}
\hline \multirow{2}{*}{$\begin{array}{c}\text { Initial Amnesia } \\
\text { Test* }\end{array}$} & \multicolumn{3}{c}{ Postamnesia Test } \\
\cline { 2 - 4 } & Generic & Particular & $\chi^{2}$ \\
Generic & \multicolumn{3}{c}{ Hypnotizable Subjects } \\
Particular & 3 & 31 & $21.44^{* *}$ \\
& \multicolumn{4}{c}{ Insusceptible Subjects } \\
Generic & 0 & 6 & 2.29 \\
Particular & 1 & 90 & 2.29 \\
\hline
\end{tabular}

${ }^{*}$ Subjects with recall $=0$ on initial amnesia test were excluded from the data analysis. $\quad{ }^{* *} p<.001(d f=1)$.

The 70 subjects who showed complete initial amnesia (56 hypnotizable and 14 insusceptible subjects) overwhelmingly showed particular recall on the postamnesia test. After lifting the amnesia suggestion, only three cases of generic recall were observed in this group, all of them hypnotizable subjects. If the postamnesia results from these completely amnesic subjects are considered, there is still no difference between hypnotizable and insusceptible subjects in the frequency of generic recall after amnesia $\left[\chi^{2}(1)=3.73, \mathrm{p}<.10\right]$.

The shift from generic to particular recall with the lifting of the amnesia suggestion is shown directly in Table 3. Here, the subjects (eliminating those who were completely amnesic on the initial test) have been jointly classified as to the nature of their recall, generic or particular, both during and after amnesia. For the hypnotizable subjects, there was a marked change from generic to particular recall with the lifting of amnesia: $79.5 \%$ of those who showed generic recall during amnesia showed particular recall later, after the suggestion was cancelled; very few of these subjects showed "backsliding" from particular recall to generic recall. This pattern of change was significant by the McNemar test $(\mathrm{p}<.001)$. The corresponding shift for the insusceptible subjects did not reach statistical significance by a binomial test $(p=.24)$.

Figure 1 shows, for the combined sample, the rela- tionship between the amount of material recalled and the occurrence of generic recall on the initial amnesia test. The frequency distribution of generic recall is plotted oniy for hypnotizable subjects, as the incidence among insusceptible subjects was too low to make such an analysis meaningful. For the hypnotizable subjects, generic recall appears to vary directly with the extent of initial amnesia, as it was shown by $40.9 \%$ of the 22 subjects who recalled only a single item during initial amnesia testing and by none of the 26 subjects who recalled seven or more items. For the insusceptible subjects, there did not seem to be any consistent relationship between generic recall and initial amnesia.

\section{DISCUSSION}

During posthypnotic amnesia, some subjects seem able to remember only fragments of the events and experiences that transpired during hypnosis. They seem to have the general idea of what they are trying to remember, that is, that it involved hands or eyes or feelings of heaviness, but they do not seem to have successfully completed the act of recall. Generic recall was found to occur significantly more often in the memory reports of hypnotizable than insusceptible subjects. Within the subgroup of hypnotizable subjects, the incidence of generic recall appeared to be lawfully related to the actual number of items recalled during amnesia, with the greatest frequency of generic recall found in those who were the most completely amnesic. Moreover, there was a marked shift from generic to particular recall following cancellation of the amnesia suggestion. Generic recall appears to be one of the manifestations of posthypnotic amnesia.

The criterion of generic recall employed in this study was rather conservative, in that any memory that the raters could identify as referring to a specific hypnotic experience was classified as particular. However, the corpus of memories labeled "particular" in this study may have included many that were actually rather fragmentary. For example, a subject may have remembered the content of an item well enough, but not its place in the temporal order of events occurring during hypnosis, or the precise nature of his overt or subjective response to the suggestion. In an earlier study by Evans, Kihlstrom, and Orne (1973), hypnotizable subjects who remembered at least some of the suggestions employed fewer words to describe the items than did comparable insusceptible subjects. In general, the memory reports of hypnotizable subjects, who were presumably respond-

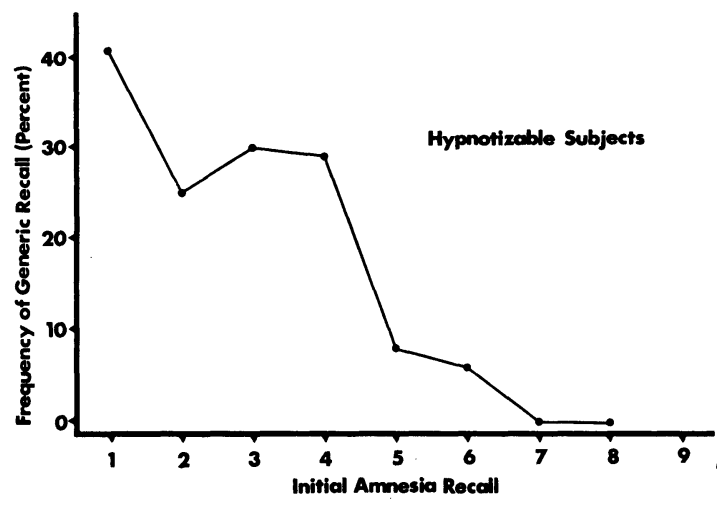

Figure 1. Frequency of Occurrence of generic recall at different points along the distribution of initial amnesia recall (hypnotizable subjects only). 
ing at least partially to the prior suggestion for amnesia, were reliably identified as such by blind raters who noticed the fragmentary, haphazard, and unfocused qualitites of their recollections. Moreover, the subject's memory may have been so fragmentary that it was not considered by the raters to refer to anything at all, even though it actually did. Such instances are observed with considerable frequency when subjects are run in individually administered hypnotic procedures, and their inclusion in the present study would certainly have increased the observed incidence of generic recall.

The tip-of-the-tongue experience and its associated feeling of knowing have been of interest to psychologists because they offer information about the act of remembering that is not always available when memory works perfectly. It is as if we need to slow things down a bit in order to better observe how our normally fast and efficient cognitive functions really operate. This was the purpose to which Brown and McNeil (1966) put their inventive technique for inducing the tip-of-the-tongue states. We believe that the use of hypnotic suggestions to produce selective temporary disruptions in the memory system can be helpful in the same way. Much as the study of generic recall for words has underscored aspects of the organization of semantic memory, it is our hope that the study of posthypnotic amnesia will help uncover the structural features and operating principles of episodic memory for events and experiences in "the real world."

\section{REFERENCES}

Brown, R., \& McNeIL, D. The "tip of the tongue" phenomenon. Journal of Verbal Learning and Verbal Behavior, 1966, 5, 325-337.
Cooper, L. M. Hypnotic amnesia. In E. Fromm \& R. E. Shor (Eds.), Hypnosis: Research developments and perspectives. Chicago: Aldine-Atherton, 1972.

Evans, F. J., Kihlstrom, J. F., \& Orne, E. C. Quantifying subjective reports during posthypnotic amnesia. Proceedings of the 81st Annual Convention of the American Psychological Association, 1973, 8, 1077-1078.

HART, J. T. Memory and the feeling-of-knowing experience. Journal of Educational Psychology, 1965, 56, 208-216.

Hilg ARd, E. R. Hypnotic susceptibility. New York: Harcourt, Brace, \& World, 1965.

Hrlgard, E. R. Posthypnotic amnesia: Experiments and theory. International Journal of Clinical and Experimental Hypnosis, 1966, 14, 104-111.

HilgaRD, E. R. Divided consciousness: Multiple controls in human thought and action. New York: Wiley-Interscience, 1977.

Kinlstrom, J. F. Models of posthypnotic amnesia. In W. E. Edmonston (Ed.), Conceptual and investigative approaches to hypnosis and hypnotic phenomena. Annals of the New York Academy of Sciences, 1977, 296, 284-301.

Kinlstrom, J. F., \& Evans, F. J. Memory retrieval processes in posthypnotic amnesia. In J. F. Kihlstrom \& F. J. Evans (Eds.), Functional disorders of memory. Hillsdale, N.J: Lawrence Erlbaum, in press.

ORNE, M. T. On the mechanisms of posthypnotic amnesia. International Journal of Clinical and Experimental Hypnosis, 1966, 14, 121-134.

ShOR, R. E., \& ORNE, E. C. Harvard group scale of hypnotic susceptibility, Form A. Palo Alto, Calif: Consulting Psychologists Press, 1962.

(Received for publication March 31, 1978.) 